\title{
Posterior percutaneous full-endoscopic cervical discectomy under local anesthesia for cervical radiculopathy due to soft-disc herniation: a preliminary clinical study
}

\author{
*Quan Wan, MD,, Daying Zhang, MD, ${ }^{*}$ Shun Li, MD, ${ }^{1}$ Wenlong Liu, MD, ${ }^{1}$ Xiang Wu, ${ }^{3}$ \\ Zhongwei Ji, MD, ${ }^{1}$ Bin Ru, MD, ${ }^{1}$ and Wenjun Cai, MD'1 \\ 'Department of Pain, Zhejiang Provincial People's Hospital, Hangzhou, Zhejiang; ' 2 Department of Pain, First Affiliated Hospital \\ of Nanchang University, Nanchang, Jiangxi; and ${ }^{3}$ Department of Anesthesiology, The Affiliated Hospital of School of Medicine of \\ Ningbo University, Ningbo, Zhejiang, China
}

\begin{abstract}
OBJECTIVE To the authors' knowledge, posterior percutaneous full-endoscopic cervical discectomy (PPFECD) has not been reported before as a procedure performed with patients under local anesthesia (LA). In this study, the authors report the outcomes of 25 patients treated by this technique, the surgical steps, and the procedure's potential advantages.

METHODS Twenty-five patients diagnosed with cervical radiculopathy due to soft-disc herniation (SDH) were treated by PPFECD. The intensities of arm and neck pain were measured using the visual analog scale (VAS) and the functional status was assessed using the Neck Disability Index (NDI) preoperatively and at 1, 3, 6, and 12 months postoperatively. Global outcome was also assessed using modified Macnab criteria, and outcomes were grouped as clinical success (excellent or good) and clinical failure (fair or poor). Complications were also recorded.
\end{abstract}

RESULTS No patient was lost to the follow-up. Significant and durable pain relief and cervical functional improvement were achieved postoperatively. Clinical success was achieved in 24 patients (96\%), including 22 excellent and 2 good outcomes at the last follow-up. No serious complications occurred.

CONCLUSIONS The authors' preliminary experience indicates that PPFECD under LA is a feasible and promising alternative for selected cases of cervical radiculopathy due to SDH, though the procedure's effectiveness and safety still need confirmation from further studies.

https://thejns.org/doi/abs/10.3171/2018.1.SPINE17795

KEYWORDS percutaneous endoscopic cervical discectomy; local anesthesia; soft-disc herniation; cervical radiculopathy

$\mathrm{R}$ ADICULAR symptoms due to degenerative changes in the cervical spine are very common clinically and arise typically from soft-disc herniation (SDH) or osteophytes. Surgical decompression may become necessary if conservative treatment fails or if paralysis occurs. Although classical anterior cervical discectomy and fusion (ACDF) and mobility-preserving posterior foraminotomy show good results, $3,7,8,16,22,27,29,30$ continuous technical optimization germane techniques should be the goal. Minimally invasive techniques can reduce trauma and promote faster rehabilitation. In recent years, posterior percutane- ous full-endoscopic cervical discectomy (PPFECD) has been reported as a new technique.,12-14,20,24,25,31 However, to the best of our knowledge, there is only very limited related literature published to date. Moreover, in the published studies, the procedures were all performed under general anesthesia (GA). Although the use of GA can provide comfortable intraoperative experience for patients, a greater risk of neurological complications may be a disadvantage. ${ }^{6}$ Beginning in 2014 we started to perform PPFECD with the patients under local anesthesia (LA). In this study, we present the outcomes of 25 selected patients

ABBREVIATIONS ACDF = anterior cervical discectomy and fusion; APFECD = anterior percutaneous full-endoscopic cervical discectomy; GA = general anesthesia; LA = local anesthesia; NDI = Neck Disability Index; PPFECD = posterior percutaneous full-endoscopic cervical discectomy; SDH = soft-disc herniation; VAS = visual analog scale.

SUBMITTED July 15, 2017. ACCEPTED January 31, 2018

INCLUDE WHEN CITING Published online June 29, 2018; DOI: 10.3171/2018.1.SPINE17795.

${ }^{*}$ Q.W. and D.Z. contributed equally to this work. 
treated by this technique, the surgical steps, and the procedure's potential advantages.

\section{Methods \\ Patient Population}

Following IRB approval and receipt of patients' written informed consent, 25 patients diagnosed with cervical radiculopathy due to SDH and who underwent PPFECD at the Department of Pain, Zhejiang Province People Hospital, between 2014 and 2016 were enrolled in this prospective study. Inclusion criteria for PPFECD included the presence of the following: 1) unilateral radiculopathy with arm or upper back pain consistent with preoperative MRI/CT findings, 2) single-level SDH, including foraminal-type and paracentral-type herniations, 3) herniations affecting C2-3 to C7-T1, and 4) failed conservative treatment of more than 6 weeks. The exclusion criteria included the presence of the following: 1) isolated neck pain, 2) clear segmental instability or deformities, 3) cervical disc herniation with calcification, 4) myelopathy, 5) central cervical disc herniation, and 6) developmental cervical spinal stenosis.

\section{Operation Technique}

All operations were performed by the same chief physician with robust experience in full-endoscopic spine surgeryafter giving patients LA. Oral diazepam was given as an anxiolytic sedative the night before the operation. Patients were situated in the prone position with their necks in slight flexion and with thin pillows placed under the forehead, chest, and abdomen. The arms and the head were fixed to the surgical bed with tape (Fig. 1A). An intravenous route was opened on the hand. Electrocardiography, pulse oxygen saturation monitoring, and blood pressure monitoring were performed. The skin entry point was marked (Fig. 1B) according to the herniation location shown on preoperative CT and MRI, with a self-made ferric locating grid used under posterior-anterior radiographic control, usually the surface projection of the superior margin of the inferior lamina of the targeted segment near the medial border of the facet joint on the affected side.

Patients received dexmedetomidine for anxiety reduction, sedation, and pain control in a loading dose of $1 \mu \mathrm{g}$ $\times \mathrm{kg}^{-1}$ for 10 minutes when the operation started, followed by a maintenance dose of $0.2-0.7 \mu \mathrm{g} \times \mathrm{kg}^{-1} \times \mathrm{hr}^{-1}$ intraoperatively, which could be adjusted according to each patient's needs. All of the operating instruments and optics were supplied by Joimax. After sterilization of the surgical field, an 18-gauge puncture needle was inserted, under radiographic control, through the skin entry point until the tip reached the bone surface of the inferior lamina (Fig. 1C), and, at the same time, $10 \mathrm{ml}$ of $1 \%$ lidocaine was injected along the puncture trajectory for local anesthesia. Next, a 10-mm transverse incision was made, a guidewire was placed, and the needle was withdrawn. After sequential dilation along the guidewire, an oblique-type working channel (length $171 \mathrm{~mm}$, outer diameter $7.5 \mathrm{~mm}$, and inner diameter $6.9 \mathrm{~mm}$ ) was introduced via the dilator (Fig. 1D and $\mathrm{E}$ ). A $30^{\circ}$ angled endoscope (outer diameter $6.3 \mathrm{~mm}$ ) with an intraendoscope eccentric working canal (diameter $3.7 \mathrm{~mm}$ ) was introduced. Further operative steps were
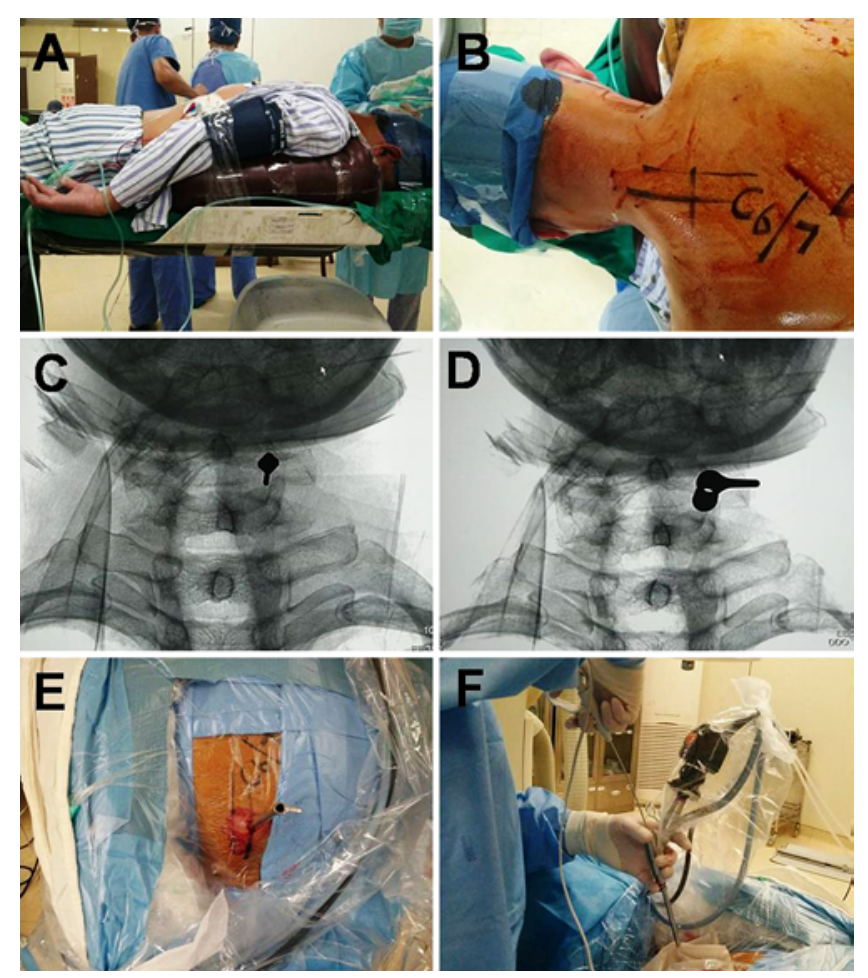

FIG. 1. A: Patient positioning. B: Positioning of the skin entry point. C: The puncture needle reached the predetermined position (the superior margin of the inferior lamina near the medial border of the affected side's facet joint). D: Placement of the working channel (anteroposterior view). E: The working channel with a 7.5-mm outer diameter. F: The surgical procedure. Figure is available in color online only.

performed under visual control and continuous irrigation with a $0.9 \%$ saline solution (Video 1 ).

VIDEO 1. Endoscopic manipulation during operative steps of the PPFECD. Copyright Zhejiang Provincial People's Hospital. Published with permission. Click here to view.

First, under endoscopic guidance, two adjacent laminas and the affected side's facet joint, which formed a V shape, were clearly exposed using the tissue forceps and a 40-cm bipolar radiofrequency coagulator with a flexible tip (Trigger-Flex Bipolar System, Elliquence). Then, bone was drilled using the Joimax Shrill-Shaver and typically a diamond drill with a 3.5-mm-diameter ball tip (Fig. 2B). For most patients, only the lateral part of the inferior lamina was drilled (Fig. 3E and F), whereas the medial part of the facet joint (not more than 50\%) or the lateral part of the superior lamina was drilled in a small number of patients depending on the pathology. After the lateral edge of the dural sac with its outgoing nerve root was exposed, in order to reduce any intraoperative pain, an additional $5 \mathrm{ml}$ of $0.25 \%$ ropivacaine was injected into the epidural space via the working channel after the saline solution and blood inside were drained. Then the epidural venous plexus was coagulated using a bipolar radiofrequency coagulator to maintain a clear visual field. The posteriorly protruding nucleus pulposus, usually located in the axillary direction of the nerve root, could be resected using the tissue forceps (Fig. 2C). After the nerve root and dural 

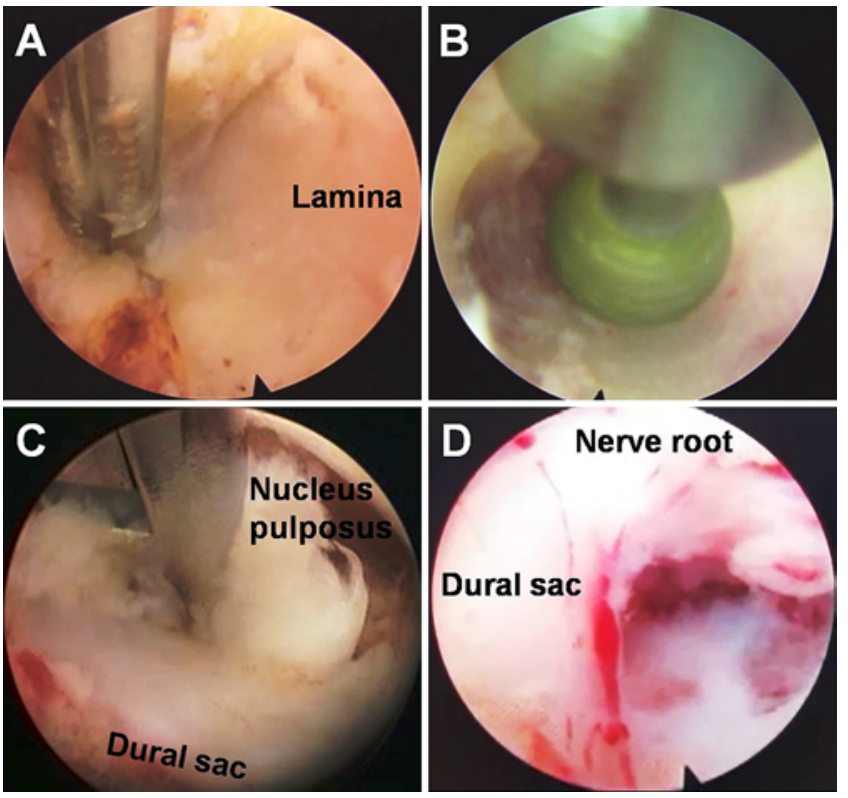

FIG. 2. A: Removal of the soft tissue with the bipolar radiofrequency coagulator and exposure of the inferior lamina. B: Laminoforaminotomy using a 3.5-mm diamond drill. C: Exposure and resection of the posteriorly protruding nucleus pulposus located in the axillary direction of the nerve root. D: Freed cervical dural sac and nerve root after full decompression. Figure is available in color online only.

sac were adequately decompressed (Fig. 2D), the working channel was carefully removed, and the skin was closed with a single stitch.

Patients were discharged on postoperative day 3 if there was no sign of postoperative infection, epidural hematoma, or nerve injury. They were advised to wear a neck collar for 4 weeks postoperatively.

\section{Outcome Evaluation}

Patients were clinically followed regularly by telephone. Arm and neck pain intensity was measured using the visual analog scale (VAS), and the functional status was assessed using the Neck Disability Index (NDI) preoperatively and $1,3,6$, and 12 months postoperatively. The global outcome was also assessed using the modified Macnab criteria, ${ }^{18}$ and outcomes were grouped as clinical success (excellent or good outcome) and clinical failure (fair or poor outcome). The modified Macnab criteria are as follows: excellent: no pain and no restriction of activity; good: occasional pain, relief of presenting symptoms, and able to return to normal work; fair: improved functional capacity but handicapped by intermittent pain of sufficient severity to curtail work or leisure activities; and poor: no improvement or insufficient improvement to enable increased activities or reoperation at the same level required. Complications were also recorded.

\section{Statistical Analysis}

Statistical analysis was performed using IBM SPSS 20.0 (IBM Corp.). The Wilcoxon rank-sum test and the Mann-Whitney U-test were applied for the comparison of
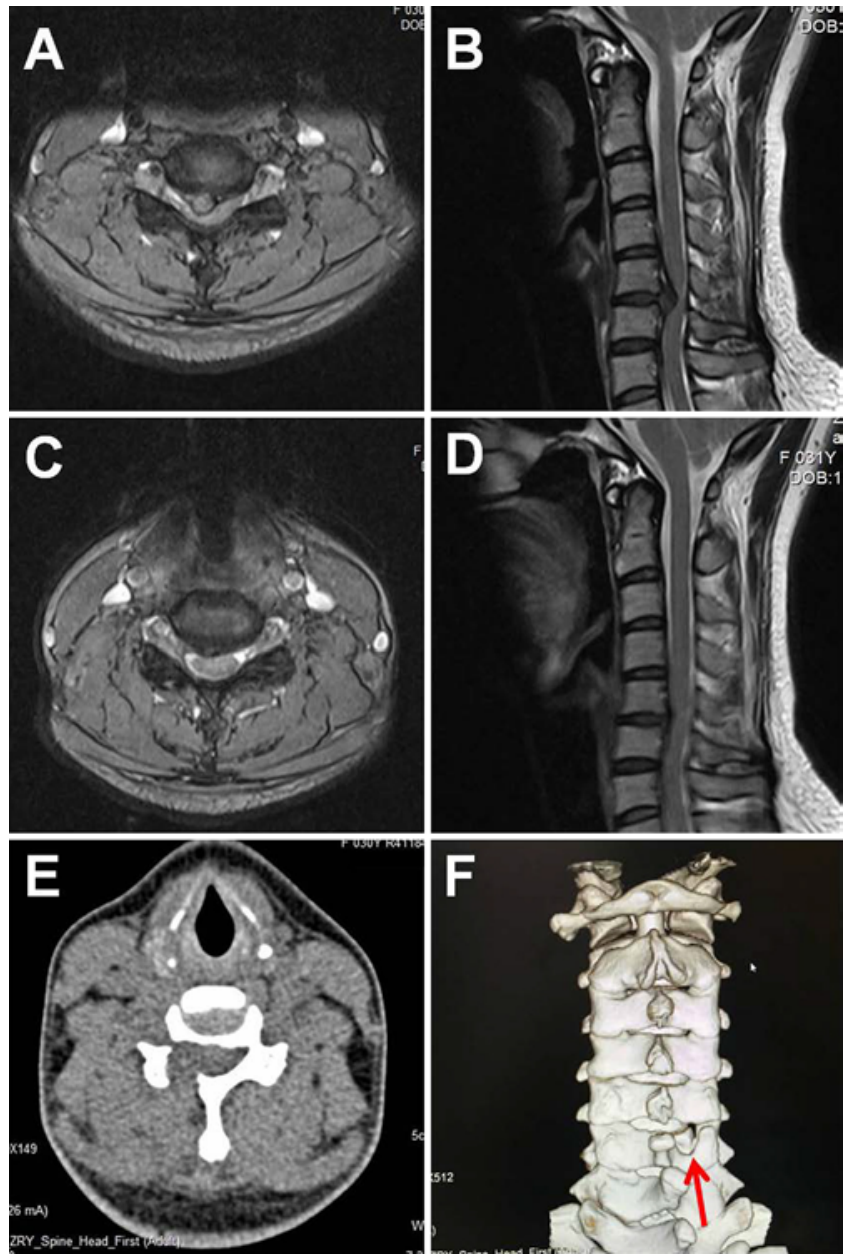

FIG. 3. A and B: Preoperative MR images showing a large soft paracentral herniated disc. C and D: Postoperative (month 3) MR images demonstrating adequate removal of the ruptured disc and the decompression of the dural sac, although a residual portion of the annulus forming a capsule around the herniated nucleus remains. $E$ and F: Axial CT scan and 3-D reconstruction after PPECFD showing that the lateral part of the inferior lamina (red arrow) of the target segment was resected. Figure is available in color online only.

pre- and postoperative results and comparison of results in the group at various times. $\mathrm{p}<0.05$ was considered statistically significant.

\section{Results}

\section{Baseline Characteristics}

Of the 25 patients, 14 were men and 11 were women. Their age ranged from 27 to 57 years (mean 38 years). The duration of symptoms ranged from 2 to 10 months (mean 5.5 months). In addition to radicular pain of the arm or shoulder, 16 patients had upper-extremity numbness, 11 patients had muscle weakness, and 12 patients had weakened tendon reflex. Nine operations were performed at C4-5, 10 at C5-6, 4 at C6-7, and 2 at C7-T1. The imaging studies showed that 12 cervical disc herniations were the foraminal type and 13 were the paracentral type, and 15 were left sided and 10 were right sided. 


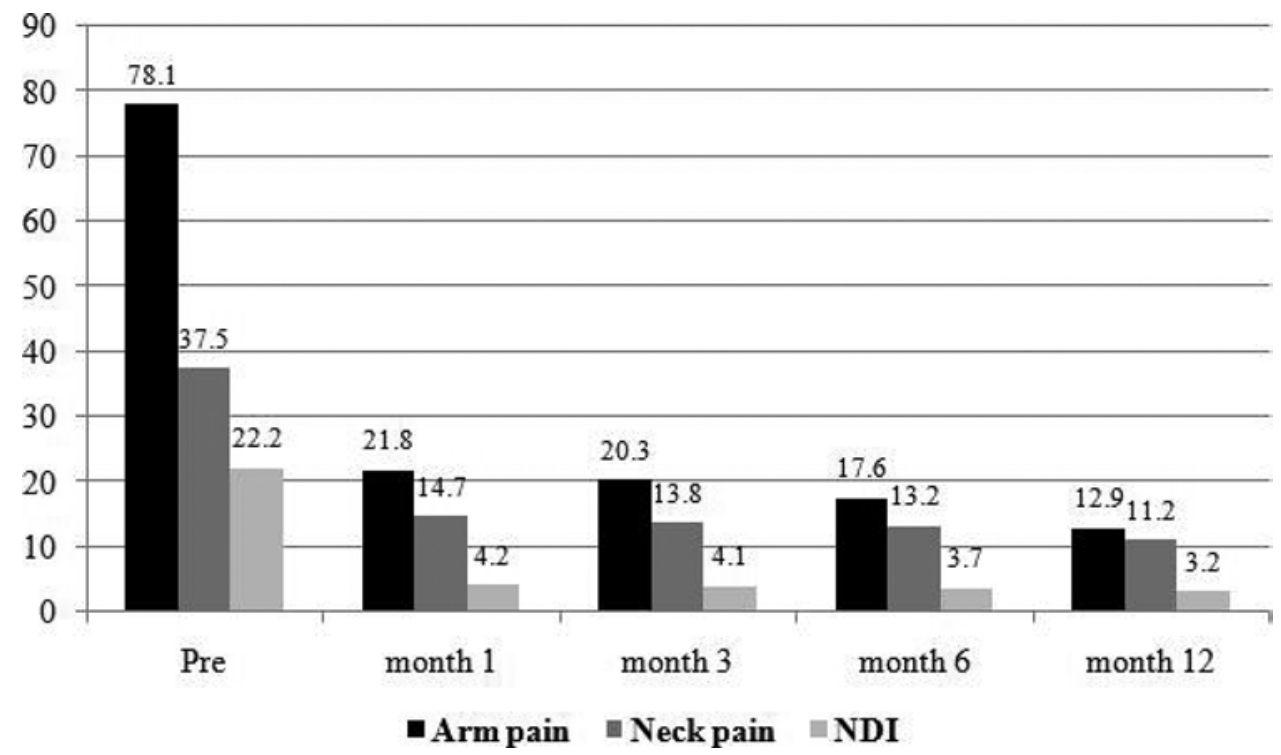

FIG. 4. Mean VAS arm and neck pain scores and mean NDI scores for 25 patients treated by PPFECD.

\section{Clinical Outcome}

The mean operative time was 90 minutes (range 75120 minutes). There was no measurable blood loss. Postoperatively, all 25 patients completed the follow-up of 12 months. The courses of VAS-rated arm and neck pain and NDI-rated cervical function are shown in Fig. 4. There was a constant and significant $(\mathrm{p}<0.05)$ reduction of pain score over time and improvement of cervical function. At postoperative month 1 , clinical success was achieved in 24 patients (96\%), including 22 excellent outcomes and 2 good outcomes according to the Macnab criteria (Fig. 5). The only patient with a fair outcome underwent an ACDF at 5 weeks postoperatively. During the follow-up, at postoperative month 3 , one patient experienced increased arm pain after a pain-free period. Cervical MRI and CT examinations demonstrated no recurrent disc herniation. His symptoms were relieved after he underwent ultrasoundguided selective nerve root block and trigger-point dry needling. No patients needed reoperation due to recurrent disc herniation or symptom deterioration. As Fig. 5 shows, by 12 months postoperatively, clinical success was maintained in 24 patients (96\%), including 22 with excellent outcome and 2 with good outcome.

\section{Complications}

There were no serious intraoperative or postoperative complications, such as dural sac tear, cervical spinal cord or nerve root injury, postoperative bleeding or hematoma formation, infection, thrombosis, or postoperative axial neck pain. Deterioration of existing symptoms did not occur in any case.

\section{Discussion}

In this current study, we report on the clinical outcomes of 25 patients who underwent PPFECD under LA. All patients experienced pain relief and cervical function improvement of different degrees postoperatively. Clinical success was achieved in a majority of patients $(24 / 25,96 \%)$ at the last follow-up. Our outcome compares with those previously reported $(85 \%-95 \%)$ for PPFECD, allowing for variability in clinical demographic characteristics of patients, follow-up duration, different pain scores, and the definition of good outcomes. ${ }^{4,12-14,20,24,25,31}$ However, due to the small size of our population and lack of a control group, our current outcomes cannot yet be compared with those of classical ACDF, traditional posterior cervical surgery, anterior percutaneous full-endoscopic cervical discectomy (APFECD), and PPFECD under GA. However, in our opinion, as long as appropriate candidates are selected and the nerve root or dural sac is adequately decompressed intraoperatively, comparative effectiveness could be achieved by PPFECD under LA. The published recurrence rate after PPFECD ranges from 3.4\% to 6.7\%.23,24 Unlike ACDF, the possibility of recurrences can never be totally ruled out with PPFECD. No patients experienced recurrent disc herniation of the surgical segment in our study, which might be a reflection of the relatively short follow-up period. As time passes, recurrence may occur in some of these patients. However, revisions still could be performed with appropriate indications by PPFECD. It is worth noting that, in contrast to previous PPFECD series, $, 12-14,20,24,25,31$ we only removed the lateral part of the inferior lamina in most patients. Using tissue forceps, we could almost entirely resect the posteriorly protruding nucleus pulposus through the bone window, in the axillary direction of the nerve root, except for a small portion of herniation in the upper lateral direction of the nerve root. Thus, less trauma can be inflicted while the effectiveness of the procedure is not reduced. It has been reported that excessive bony resection of the facet joint and lamina may decrease the segmental stability of the cervical spine and increase postoperative scar formation.

As for the safety, no serious complications occurred in the current study. Classical procedures will yield good 


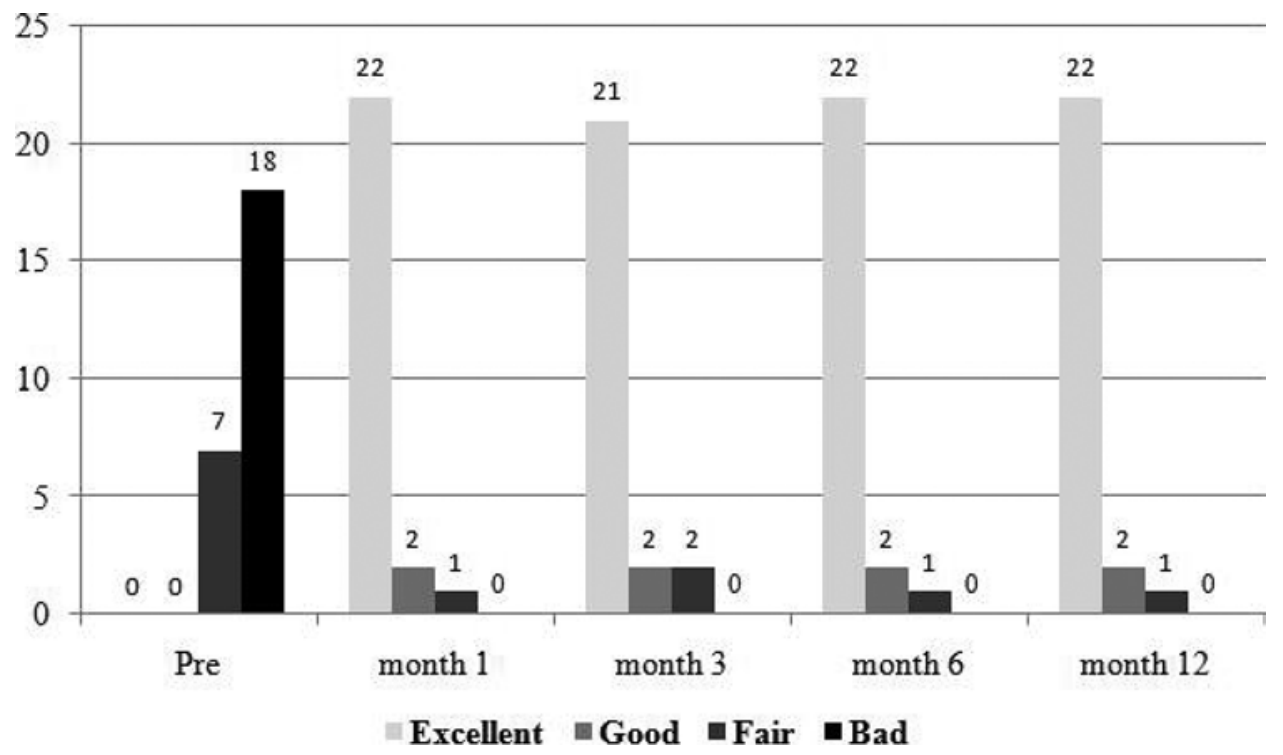

FIG. 5. Clinical outcomes in 25 patients treated by PPFECD according to modified Macnab criteria.

results when indications are taken into consideration. However, ACDF may have access-related complications, loss of intervertebral height, pseudarthrosis, and adjacentsegment disease. $5,11,17,19,21,26,28$ Access-related neck pain and intraoperative bleeding are considered disadvantages of the traditional posterior foraminotomy. ${ }^{9,10}$ By contrast, the PPFECD has the following advantages, which could improve the surgical safety: facilitation for the surgeon by excellent presentation of the anatomical structures; good illumination and expanded field of vision thanks to $30^{\circ}$ optics; maintained mobility and stability for the patient due to lack of interbody infusion and reduced operative trauma; almost no access-related neck pain due to less muscle stripping; reduced intraoperative bleeding due to continuous fluid flow and application of the low-energy bipolar radiofrequency; and no risk of anterior approachrelated complications. The APFECD procedure, $, 1,23,31$ another minimally invasive cervical full-endoscopic surgery, requires access through the disc anterior to the pathology, which violates anterior structures, such as the annulus and nucleus. This procedure may also eventually reduce the stability of the disc. There is also a risk of vascular, nerve, or esophageal injury similar to that of the ACDF. In addition, it is also very difficult to insert the working cannula in cases with vertical intervertebral distance of less than $4 \mathrm{~mm}$, a large anterior vertebral osteophyte, or disc calcification. However, there is a risk of nerve root, dural sac, or spinal cord injury during the PPFECD, which largely depends on the surgeons' experience and skill.

To our knowledge, the PPFECD under LA has not been reported before now, although LA has been recommended by most surgeons in percutaneous lumbar full-endoscopic surgery. The PPFECD under GA has been reported in several previous published articles. ${ }^{4,12-14,20,24,25,31}$ GA may offer patients a comfortable intraoperative experience, but it renders them unable to communicate with the doctor. Together with potential cervical root anomalies, the incidence of neurological complications is undoubtedly increased. If
GA is used, intraoperative neurophysiological monitoring should be considered; thus, the medical costs would be increased. In our cases, all the surgeries were performed under LA. During the operation, we used $10 \mathrm{ml}$ of $1 \%$ lidocaine injected along the trajectory for local infiltration anesthesia, and an additional $5 \mathrm{ml}$ of $0.25 \%$ ropivacaine was injected into the epidural space through the working channel after the resection of ligamentum flavum, which could be regarded as a kind of "epidural anesthesia" that can preserve motor function and only blocks sensation. Thus, patients could move their fingers and legs when the surgeons required, which is a good means of identifying cervical nerve injury. ${ }^{6}$ In our study, no nerve root, dural sac, or spinal cord injury occurred. On the other hand, LA also has its disadvantages. First, some patients still feel intraoperative pain to some degree, although that degree is tolerable. Moreover, even if there is no pain, patients usually feel nervous and uncomfortable intraoperatively when they are awake, which might not only lead to elevated blood pressure and an increased heart rate, but also make patients' experience unpleasant, with being kept in the prone position for a long time and hearing the surgical instruments. Based on this, dexmedetomidine was was also used intraoperatively in our cases. Dexmedetomidine, a selective alpha-2 adrenergic receptor agonist, exhibits sympatholytic, sedative, and analgesic effects and has several advantages for use as a sedative. First, the drug does not cause respiratory depression, which is especially suited for surgical patients in the prone position surgery. ${ }^{15}$ Another advantage is easy arousability of the treated patients, making them calm and cooperative. These characteristics make dexmedetomidine an appropriate sedative and supplementary analgesic drug for PPFECD under LA. Transient heart rate slowing (less than 50 beats per minute) occurred in three cases $(3 / 25,12 \%)$. The heart rate returned to normal in two cases after the infusion rate of dexmedetomidine was slowed, while the third patient recovered after atropine injection. 


\section{Limitation}

Our study is a case series of small sample size, has a relatively short follow-up period, and lacks a control group. Postoperative radiological assessment was not adequate to evaluate the removal of herniation and the effect on the stability of the cervical spine.

\section{Conclusions}

Our preliminary experience indicates that PPFECD under LA is a feasible and promising alternative for selected cases with cervical radiculopathy due to $\mathrm{SDH}$, although the procedure's effectiveness and safety require further confirmation from randomized controlled trials with large sample size and a longer follow-up period.

\section{References}

1. Ahn Y, Lee SH, Chung SE, Park HS, Shin SW: Percutaneous endoscopic cervical discectomy for discogenic cervical headache due to soft disc herniation. Neuroradiology 47:924-930, 2005

2. Ahn Y, Lee SH, Shin SW: Percutaneous endoscopic cervical discectomy: clinical outcome and radiographic changes. Photomed Laser Surg 23:362-368, 2005

3. Bohlman HH, Emery SE, Goodfellow DB, Jones PK: Robinson anterior cervical discectomy and arthrodesis for cervical radiculopathy. Long-term follow-up of one hundred and twenty-two patients. J Bone Joint Surg Am 75:12981307,1993

4. Chu L, Chen L, Wang Y, Ke ZY, Che F, Cheng Y, et al: [Posterior percutaneous full endoscopic cervical discectomy for cervical intervertebral disc herniation.] J Chongqing Med Univ 39:219-222, 2014 (Chinese)

5. Epstein NE: A review of laminoforaminotomy for the management of lateral and foraminal cervical disc herniations or spurs. Surg Neurol 57:226-234, 2002

6. Fang G, Ding Z, Song Z: Comparison of the effects of epidural anesthesia and local anesthesia in lumbar transforaminal endoscopic surgery. Pain Physician 19:E1001-E1004, 2016

7. Grieve JP, Kitchen ND, Moore AJ, Marsh HT: Results of posterior cervical foraminotomy for treatment of cervical spondylitic radiculopathy. Br J Neurosurg 14:40-43, 2000

8. Henderson CM, Hennessy RG, Shuey HM Jr, Shackelford EG: Posterior-lateral foraminotomy as an exclusive operative technique for cervical radiculopathy: a review of 846 consecutively operated cases. Neurosurgery 13:504-512, 1983

9. Kawaguchi Y, Matsui H, Tsuji H: Back muscle injury after posterior lumbar spine surgery. A histologic and enzymatic analysis. Spine (Phila Pa 1976) 21:941-944, 1996

10. Kawaguchi Y, Matsui H, Tsuji H: Back muscle injury after posterior lumbar spine surgery. Part 2: Histologic and histochemical analyses in humans. Spine (Phila Pa 1976) 19:2598-2602, 1994

11. Kettler A, Wilke HJ, Claes L: Effects of neck movements on stability and subsidence in cervical interbody fusion: an in vitro study. J Neurosurg 94 (1 Suppl):97-107, 2001

12. Kim CH, Chung CK, Kim HJ, Jahng TA, Kim DG: Early outcome of posterior cervical endoscopic discectomy: an alternative treatment choice for physically/socially active patients. J Korean Med Sci 24:302-306, 2009

13. Kim CH, Kim KT, Chung CK, Park SB, Yang SH, Kim SM, et al: Minimally invasive cervical foraminotomy and diskectomy for laterally located soft disk herniation. Eur Spine J 24:3005-3012, 2015
14. Kim CH, Shin KH, Chung CK, Park SB, Kim JH: Changes in cervical sagittal alignment after single-level posterior percutaneous endoscopic cervical diskectomy. Global Spine J 5:31-38, 2015

15. Kim KH: Safe sedation and hypnosis using dexmedetomidine for minimally invasive spine surgery in a prone position. Korean J Pain 27:313-320, 2014

16. Krupp W, Schattke H, Müke R: Clinical results of the foraminotomy as described by Frykholm for the treatment of lateral cervical disc herniation. Acta Neurochir (Wien) 107:22-29, 1990

17. Kulkarni V, Rajshekhar V, Raghuram L: Accelerated spondylotic changes adjacent to the fused segment following central cervical corpectomy: magnetic resonance imaging study evidence. J Neurosurg 100 (1 Suppl Spine):2-6, 2004

18. Macnab I: Negative disc exploration. An analysis of the causes of nerve-root involvement in sixty-eight patients. J Bone Joint Surg Am 53:891-903, 1971

19. Maiman DJ, Kumaresan S, Yoganandan N, Pintar FA: Biomechanical effect of anterior cervical spine fusion on adjacent segments. Biomed Mater Eng 9:27-38, 1999

20. Oertel JM, Philipps M, Burkhardt BW: Endoscopic posterior cervical foraminotomy as a treatment for osseous foraminal stenosis. World Neurosurg 91:50-57, 2016

21. Pedram M, Castagnera L, Carat X, Macouillard G, Vital JM: Pharyngolaryngeal lesions in patients undergoing cervical spine surgery through the anterior approach: contribution of methylprednisolone. Eur Spine J 12:84-90, 2003

22. Riew KD, Cheng I, Pimenta L, Taylor B: Posterior cervical spine surgery for radiculopathy. Neurosurgery 60 (1 Supp1 1):S57-S63, 2007

23. Ruetten S, Komp M, Merk H, Godolias G: Full-endoscopic anterior decompression versus conventional anterior decompression and fusion in cervical disc herniations. Int Orthop 33:1677-1682, 2009

24. Ruetten S, Komp M, Merk H, Godolias G: Full-endoscopic cervical posterior foraminotomy for the operation of lateral disc herniations using 5.9-mm endoscopes: a prospective, randomized, controlled study. Spine (Phila Pa 1976) 33:940-948, 2008

25. Ruetten S, Komp M, Merk H, Godolias G: A new fullendoscopic technique for cervical posterior foraminotomy in the treatment of lateral disc herniations using $6.9-\mathrm{mm}$ endoscopes: prospective 2-year results of 87 patients. Minim Invasive Neurosurg 50:219-226, 2007

26. Türeyen K: Disc height loss after anterior cervical microdiscectomy with titanium intervertebral cage fusion. Acta Neurochir (Wien) 145:565-570, 2003

27. Villavicencio AT, Pushchak E, Burneikiene S, Thramann JJ: The safety of instrumented outpatient anterior cervical discectomy and fusion. Spine J 7:148-153, 2007

28. Wang MC, Chan L, Maiman DJ, Kreuter W, Deyo RA: Complications and mortality associated with cervical spine surgery for degenerative disease in the United States. Spine (Phila Pa 1976) 32:342-347, 2007

29. Woertgen C, Rothoerl RD, Henkel J, Brawanski A: Long term outcome after cervical foraminotomy. J Clin Neurosci 7:312-315, 2000

30. Wright IP, Eisenstein SM: Anterior cervical discectomy and fusion without instrumentation. Spine (Phila Pa 1976) 32:772-775, 2007

31. Yang JS, Chu L, Chen L, Chen F, Ke ZY, Deng ZL: Anterior or posterior approach of full-endoscopic cervical discectomy for cervical intervertebral disc herniation? A comparative cohort study. Spine (Phila Pa 1976) 39:1743-1750, 2014

\section{Disclosures}

The authors report no conflict of interest concerning the materi- 
als or methods used in this study or the findings specified in this paper.

\section{Author Contributions}

Conception and design: Li, Wan, Zhang. Acquisition of data: Li, Wan, Zhang, Liu, Ji, Ru, Cai. Analysis and interpretation of data: Li, Wan, Zhang, Liu, Ji, Ru. Drafting the article: Li, Wan, Zhang. Critically revising the article: all authors. Reviewed submitted version of manuscript: all authors. Approved the final version of the manuscript on behalf of all authors: Li. Statistical analysis: $\mathrm{Li}$, Wan, Zhang, Ji. Administrative/technical/material support: Wan, Zhang, Liu, Wu, Cai. Study supervision: Li, Wan, Zhang, Liu, Wu.

\section{Supplemental Information}

Videos

Video 1. https://vimeo.com/259666297.

\section{Correspondence}

Shun Li: Zhejiang Provincial People's Hospital, Zhejiang, China. lishunttk@126.com. 